\title{
Erratum to: Strabismus
}

\author{
Burton J. Kushner
}

\section{Erratum to:}

\section{B. Kushner, Strabismus, DOI 10.1007/978-3-319-63019-9}

This book was inadvertently published with typo errors in chapters $2,4,5,6,7,8,10,11,12,13,16$, $18,20,21$.

These errors were corrected and figures 10.25, 20.1 has been updated in respective chapters.

The updated online version of these chapters can be found at https://doi.org/10.1007/978-3-319-63019-9_2 https://doi.org/10.1007/978-3-319-63019-9_4 https://doi.org/10.1007/978-3-319-63019-9_5 https://doi.org/10.1007/978-3-319-63019-9_6 https://doi.org/10.1007/978-3-319-63019-9_7 https://doi.org/10.1007/978-3-319-63019-9_8 https://doi.org/10.1007/978-3-319-63019-9_10 https://doi.org/10.1007/978-3-319-63019-9_11 https://doi.org/10.1007/978-3-319-63019-9_12 https://doi.org/10.1007/978-3-319-63019-9_13 https://doi.org/10.1007/978-3-319-63019-9_16 https://doi.org/10.1007/978-3-319-63019-9_18 https://doi.org/10.1007/978-3-319-63019-9_20 https://doi.org/10.1007/978-3-319-63019-9_21 